\title{
Urinary incontinence in Norwegian nursing home residents
}

\author{
Liv Heidi Skotnes ${ }^{1,2^{*}}$, Ragnhild Omli ${ }^{2}$, Ulla Romild ${ }^{3}$, Ove Hellzèn ${ }^{1,4}$, Esther Kuhry ${ }^{5}$ \\ ${ }^{1}$ Department of Health Sciences, Mid-Sweden University, Östersund, Sweden \\ ${ }^{2}$ Department of Medicine, Division of Geriatrics, Nord-Trøndelag Health Trust, Namsos, Norway \\ ${ }^{3}$ Department of Research and Development, Nord-Trøndelag Health Trust, Namsos, Norway \\ ${ }^{4}$ Nord-Trøndelag University College, Namsos, Norway \\ ${ }^{5}$ Department of Surgery, St. Olavs Hospital, Trondheim, Norway \\ Email: " liv.heidi.skotnes@hnt.no
}

Received 16 February 2012; revised 20 March 2012; accepted 24 April 2012

\begin{abstract}
Urinary incontinence is a multi-factorial condition that has a high impact on older persons living in nursing homes. While urinary incontinence is common, only a small percentage of nursing home residents have an official diagnosis. Factors influencing urinary incontinence in this population are poorly understood. The aim of this study was to evaluate the prevalence of urinary incontinence in Norwegian nursing home residents and to study the factors associated with urinary incontinence in this population. Residents from six different nursing homes were included in this study. Data on sex, age, medication, comorbid illnesses, urinary incontinence and the use of absorbent pads was collected. Barthel's Index of Activities of Daily Living (ADL) was used to estimate residents' functional levels. Post-voiding residual urine was measured by means of a portable ultrasound. A questionnaire was completed by the nursing staff for each of the residents. In total, 173 residents participated in the study. One hundred and twentytwo residents $(69 \%)$ were incontinent for urine and 144 used absorbent pads (83\%). Fourteen percent of residents used absorbent pads "just to make sure". They did not have a history of urinary incontinence. Low ADL score, dementia and urinary tract infection were significantly associated with incontinence for urine. The prevalence of urinary incontinence in Norwegian nursing homes is high. Absorbent products are frequently used without a history of urinary incontinence. Physical impairment, dementia and urinary tract infections are significantly associated with urinary incontinence.
\end{abstract}

Keywords: Nursing Home; Urinary Incontinence

\section{INTRODUCTION}

Urinary incontinence is a significant problem in nursing

\footnotetext{
${ }^{*}$ Corresponding author.
}

home residents, affecting approximately $50 \%$ to $70 \%$ of this population. Its prevalence increases progressively with age [1]. It is associated with decreased quality of life [2] and high costs for society [3]. It is also the second leading cause of institutionalization of elderly individuals [4]. Urinary incontinence has been defined by the International Continence Society as "a condition in which the involuntary loss of urine is a social and hygienic problem and is objectively demonstrable" [5]. Although more than half of all nursing home residents are affected, only $1 \%$ to $2 \%$ of women in nursing homes have an official diagnosis of urinary incontinence [6]. Also, previous studies have reported that less than $5 \%$ of older incontinent people have been evaluated by a specialist [7]. Accurate knowledge of urinary incontinence prevalence rates in nursing homes is important for policy makers and researchers [8].

A variety of factors are associated with urinary incontinence. Some factors Age-related physiological changes and illnesses can have an effect on bladder control and cause urinary frequency, urgency, urge incontinence or problems with bladder emptying. Several types of medication can also contribute to these symptoms. Nursing home residents are getting older and therefore, on average, require more assistance with daily activities, including going to the toilet [9]. Urinary incontinence associated with dementia is also a significant problem in nursing homes. Cerebral changes can cause psychological, behavioral and environmental problems and contribute to the inability to use the toilet or to ask for assistance [10].

Urinary incontinence is a challenge for staff working in nursing homes. Studies have reported that $50 \%$ of all women in nursing homes have difficulty controlling urination and need assistance when using the toilet [6]. A number of studies have shown that incontinence care is defective and nursing staff use strategies to contain incontinence rather than promoting continence [11]. Many nurses believe that urinary incontinence is a normal part 
of aging and nothing can be done to prevent it [12,13]. However, studies have shown that $70 \%$ of older people with urinary incontinence can be cured or their symptoms alleviated [14]. Knowledge about factors associated with urinary incontinence is essential when trying to improve incontinence care.

\begin{abstract}
Aims
To evaluate the prevalence of urinary incontinence in Norwegian nursing home residents.

To identify factors associated with urinary incontinence in this population.
\end{abstract}

\section{METHODS}

This study was originally designed in order to get a better understanding of bladder problems in nursing home residents. Data from this study on the association between urinary tract infections and residual urine have been published elsewhere [15,16].

\subsection{Sample}

Nursing homes resident from six different Norwegian nursing homes were included in the study. The number of residents in each nursing home varied from 16 to 70 . All residents who lived in the respective nursing homes were evaluated for inclusion. Terminally ill patients were excluded from participation. Patient that used a catheter were excluded from the current analyses.

\subsection{Data Collection}

Registered nurses (educated at the university/college) were responsible for the data collection and registration. Licensed practical nurses (educated at the upper secondary school level) were supervised to take part in the collection of data.

Information on comorbid illnesses associated with urinary incontinence and post-voiding residual urine was collected. Barthel`s Index of Activities of Daily Living was used to estimate patients functional levels $[17,18]$. The Barthel Index is a standardized functional-level scale used to score improvement in the rehabilitation of chronically ill patients. It includes 10 different activities. Points are given according to assistance provided and time required performing the activities. The maximum score is 20 . A score of 12 to 20 points indicates independence, 5 to 11 points means partial dependence, and a score less than 5 indicate total dependence.

A survey was used to collect information from nursing staff. One survey was filled out for each of the residents. The survey included several questions on comorbid illnesses, need for assistance to go to the toilet and type of assistance. Data on incontinence and the use of absorbent pads was collected.

Data on post voiding residual volume (PVR) was collected for each of the residents. Nurses at each nursing home were trained in data collection and use of the BVI 3000 ultrasound BladderScan (Diagnostic Ultrasound, Redmond, WA). Previous studies have shown that the BVI BladderScan produces conservative and valid estimates of PVR when used by trained personnel $[19,20]$. At the time of inclusion, a portable ultrasound bladder scanner was used to measure PVR. Measurements were performed twice. The first measurement was performed in the morning and the second in the late afternoon or evening. Before the measurement of residual urine, patients were instructed to empty their bladders. Nurses were instructed to perform the measurements within 10 to 15 minutes after the bladder was emptied, as previously suggested [21]. In patients who were unable to cooperate, nurses waited until there was an episode in which bladder emptying was observed to make sure the measurements were taken within 15 minutes. All measurements of PVR were performed with the patients in supine position.

Scanning was repeated until the display showed the bladder in the centre area, enabling measurements to be taken in the correct position. The result of each measurement was printed out. The average residual volume of the two measurements was used in the analyses.

\subsection{Data Analysis}

Pearson's Chi-Square test of independence was used for bivariate tests between the dependent variable and categorical variables. T-tests were used for continuous variables. Results were confirmed by Mann-Whitney's U-test in cases of skewed distributions. Analyses were performed using SPSS version 18.0 (SPSS Inc., Chicago).

\subsection{Ethical Issues}

The board of research ethics in the areas where the study was coordinated approved the study. All patients provided informed consent before participation in the study. For patients who were unable to make the decision themselves, due to for example dementia, a close family member was allowed to sign the consent. The study complies with ethical rules for human experimentation as stated in the Declaration of Helsinki [22].

\section{FINDINGS}

In total, 173 residents (51 men and 122 women) participated in the study. The mean age of the residents was $84.2( \pm 8)$ years. The mean score on the Barthel scale was 8 , indicating that patients, on average, had a high grade of dependency. Fifty-five and 61 residents, respectively, 
were totally or partially dependent on nursing staff for their activities of daily living. One hundred and twentyfour residents (72\%) needed assistance to go to the toilet.

Most residents (98\%) had one or more medical conditions affecting bladder control. Use of diuretics was common (69\%). One hundred and twenty-two residents (69\%) were incontinent for urine. For patient characteristics see Table 1.

Of all residents, 144 used absorbents pads (83\%). In total, $14 \%$ of the residents used absorbent pads "just to make sure”. They did not have a history of urinary incontinence.

There was no significant association between gender and urinary incontinence $(P=0.72)$. The Activities of Daily Living score was, as expected, significantly associated with incontinence for urine $(P<0.01)$. Of comorbid illnesses, dementia significantly increased the risk for urinary incontinence $(P=0.04)$. No significant differences in mean residual urine were observed between residents that were continent and incontinent for urine $(P$ $=0.67)$. Urinary tract infection at baseline was significantly associated with urinary incontinence $(P=0.02)$. Use of diuretics and oestrogen was not associated with the incontinence for urine. For details on factors associated with urinary incontinence see Table 2.

\section{DISCUSSION}

In the past years, characteristics of nursing homes residents have changed. Residents have, on average, become older and more reduced, both mentally and physically. They require increased assistance with activities of daily living. The prevalence of incontinence among nursing home residents is also on the rise [9].

The average score on the Barthel Index for participants in this study was 8, which indicates that residents had a high degree of physical dependence. The average age of the residents was high (84.2 years) and the majority of residents (72\%) had impaired mobility and needed assistance to come to the toilet. ADL-score was significantly associated with urinary incontinence in our study $(P<0.01)$. Impaired mobility is a known risk factor for incontinence [23]. In a cross-sectional study of nursing homes residents in Italy, residents who used a wheelchair or were bedridden were seven times more at risk for developing incontinence compared to mobile residents [1].

Cerebrovascular disorders were also common in our population. Several studies have shown that age-related changes and cerebrovascular conditions such as Apoplexia, Parkinson's disease and dementia can cause detrusor overactivity with small frequent contractions, also called "frequency". This can again cause urgency (i.e.,

Table 1. Residents characteristics.

\begin{tabular}{|c|c|c|}
\hline Characteristics & Males $(\mathrm{n}=51)$ & Females $(\mathrm{n}=122)$ \\
\hline Age $^{*}$ & $81.7 \pm 8.6$ & $84.9 \pm 7.9$ \\
\hline \multicolumn{3}{|c|}{ Activity of daily living dependency (score) ${ }^{\#}$} \\
\hline Totally dependent $(<5)$ & $14(28)$ & $41(34)$ \\
\hline Partially dependent (5 - 11) & $21(41)$ & $40(33)$ \\
\hline Independent (12 - 20) & $16(32)$ & $41(34)$ \\
\hline \multicolumn{3}{|l|}{ Comorbid conditions $^{\#}$} \\
\hline Dementia & $23(45)$ & $52(43)$ \\
\hline Parkinson's disease & $3(8)$ & $6(7)$ \\
\hline Constipation & $25(49)$ & $46(38)$ \\
\hline Diabetes mellitus & $8(16)$ & $25(21)$ \\
\hline Prostatic hypertrophy & $14(28)$ & \\
\hline Apoplexia & $19(48)$ & $38(38)$ \\
\hline Incontinence & 35 (73) & $87(68)$ \\
\hline \multicolumn{3}{|l|}{ Medication $^{\#}$} \\
\hline Diuretica & $28(55)$ & $61(50)$ \\
\hline Oestrogen & & $10(6)$ \\
\hline
\end{tabular}

*Data are given as mean (SD); ${ }^{*}$ Data are given as n (\%). 
Table 2. Residents characteristics vs incontinence.

\begin{tabular}{|c|c|c|c|}
\hline Incontinence & Yes $(n=122)$ & No $(\mathrm{n}=51)$ & $P$-value \\
\hline $\operatorname{Sex}^{\#}$ & & & 0.72 \\
\hline Female & 87 (73) & 35 (69) & \\
\hline Men & $35(29)$ & $16(31)$ & \\
\hline Activity of daily living dependency ${ }^{\#}$ & & & $<0.01$ \\
\hline Totally dependent & $55(45)$ & 0 & \\
\hline Partially dependent & $46(38)$ & $15(29)$ & \\
\hline Independent & $21(17)$ & $36(71)$ & \\
\hline \multicolumn{4}{|l|}{ Comorbid conditions $^{\#}$} \\
\hline Dementia & $59(48)$ & $16(31)$ & 0.04 \\
\hline Constipation & $48(39)$ & $23(23)$ & 0.48 \\
\hline Diabetes mellitus & $24(20)$ & $9(18)$ & 0.75 \\
\hline Prostatic hypertrophy & $10(8)$ & $4(8)$ & 0.93 \\
\hline Apoplexia & $40(33)$ & $17(33)$ & 0.94 \\
\hline Parkinsons' disease & $7(8)$ & $2(7)$ & 0.65 \\
\hline Residual urine ${ }^{*}$ & $94.2 \pm 89.4$ & $101.1 \pm 109.7$ & 0.67 \\
\hline Urinary tract infection on baseline ${ }^{\#}$ & $24(20)$ & $3(6)$ & 0.02 \\
\hline \multicolumn{4}{|l|}{ Medication $^{\#}$} \\
\hline Diuretica & $58(48)$ & $31(61)$ & 0.11 \\
\hline Oestrogen & $9(7)$ & $1(2)$ & 0.16 \\
\hline
\end{tabular}

*Data are given as mean (SD); ${ }^{*}$ Data are given as n (\%).

abrupt urge to void before the bladder is full) and urge incontinence [4]. Resnick and colleagues performed multi-channel video-urodynamics on 94 incontinent nursing home residents [24]. They found that detrusor overactivity was the predominant cause for incontinence in $61 \%$ of the residents. Half of those with detrusor overactivity had associated impaired detrusor contractility. A combination of detrusor overactivity and impaired contractility presents particular challenges, since it will give symptoms such as frequency, urgency, urge incontinence and incomplete emptying. Among the women included in the study by Resnick, 21\% had stress incontinence. Twenty-nine per cent of men had evidence of outlet obstruction. Thirty-five percent of all residents had more than one of these diagnoses [24]. According to Taylor et al. [25], impaired detrusor contractility is an underdiagnosed geriatric condition that can contribute to urinary frequency and nocturia by causing incomplete emptying.

Common medical conditions in the elderly play an important role in bladder function. More than $50 \%$ of patients with diabetes mellitus have bladder dysfunction
[26]. Several clinical studies have reported detrusor overactivity and hypersensitivity as the most frequent findings in urodynamics performed in patients with diabetes $[27,28]$. Other studies have described loss of sensation, increased capacity, decreased contractility and increased post-voiding residual urine [29,30]. Obstipation can cause urinary incontinence and urinary retention [25]. Obstipation was also common in residents included in our study [4]. However, no significant association with urinary incontinence was found.

Polypharmacy is common among residents in nursing homes and some types of medication can contribute to post-voiding residual urine and incontinence [31,32]. A number of residents in this study used diuretics. Diuretics can cause urge and increased frequency of micturition $[33,34]$. Atrophic vaginitis is a common condition in older women. It is caused by loss of the hormone oestrogen. Women with atrophic vaginitis will often complain of urinary frequency and urinary incontinence [4]. In our study, dementia and physical impairment were associated with urinary incontinence. Prior studies have also shown that dementia and physical impairment are 
associated with incontinence for urine [8]. The prevalence of urinary tract infection is high among nursing homes residents and is associated with deterioration and development of urinary incontinence [35]. This was also found in the recent study.

To understand the conditions that contribute to urinary incontinence is important for good clinical practice in nursing homes. Members of the nursing staff need to gain adequate knowledge of the causes of urinary incontinence, urgency and frequency in the elderly. A possible consequence of inadequate knowledge is promotion of urinary incontinence by telling residents to wait or ignoring a request for toilet assistance. Many nursing homes residents may have been misunderstood when they have asked for assistance to come to the toilet with short intervals, since nurses are not always aware of the causes of incontinence. They may believe that a request to come to the toilet is attention seeking behaviour [36]. Several studies have highlighted bad practice, such as ignoring a request for assistance to the toilet, telling people to wait and telling them to use absorbent pads instead of trying to prevent incontinence [9,37]. Schnelle and colleagues interviewed 117 incontinent residents in nursing homes about their preferences for toileting. Residents who needed assistance with toileting reported that they preferred an average of 2.4 toileting assists per day and that they received an average of 1.7. Twenty-three percent reported that they received no toilet assists and some residents had learned not to expect more frequent care [38]. Resnick and colleagues performed a qualitative study in a nursing home. They found that the attitude of nursing staff was a major contributor to urinary incontinence. Various reasons for not providing help in toileting are mentioned. Common reasons are nurses not answering call lights or being unable to find help if they are taken up with others business. Nursing staff thought that preventing urinary incontinence had a low priority compared to other things.

Lack of knowledge about urinary incontinence and negative attitude about effectiveness of incontinence treatment among nursing staff, together with adhering to toileting schedules or ignoring requests for toileting were mentioned by directors of nursing homes as a reason for inadequate continence care [39]. The institutional culture of urinary incontinence in nursing homes is characterized by rituals and routines and the care is little or not individualized. Toileting routine is often initiated when nursing staff have rounds or not when residents are in need [40-42]. In a qualitative study in long-term care, women told that the reply to their request for toilet assistance was influenced by how busy the nursing staff was. It happened that assistance came too late [42]. Several studies have shown that nursing staff has not been proactive enough with regard to prevention of incontinence.
Continence assessment by nursing staff has traditionally focussed on selecting the appropriate absorbent pads, rather than on treatment of incontinence [43].

In the current study, $14 \%$ of nursing home residents used absorbent pads without a diagnosis of urinary incontinence. Many nurses are convinced that older people accept urinary incontinence as a normal consequence of ageing. A study has shown that residents get labelled as incontinent for urine after only one episode of leakage [11]. Also, residents who are not know to have urinary incontinence can ask for absorbent pads through fear of being incontinent or if they have had a period of urinary incontinence in their history [11].

Previous studies have shown that older people with urinary incontinence can be cured or their symptoms alleviated with adequate approach and treatment [14]. To prevent and treat urinary incontinence among residents is very important. Eighty-one percent of nursing home residents who presented with incontinence have a reversible cause of incontinence at the time of onset [13]. Knowledge about factors that influence bladder control is therefore important.

\section{CONCLUSION}

The prevalence of urinary incontinence in nursing homes is high. Absorbent products are frequently used without a history of urinary incontinence. Physical impairment, dementia and urinary tract infections are significantly associated with urinary incontinence.

\section{REFERENCES}

[1] Aggazotti, G., Pesce, F., Grassi, D., Fantuzzi, G., Righi, E., De Vita, D., Santacroce, S. and Artibani, W. (2000) Prevalence of urinary incontinence among institutionalized patients: A cross-sectional epidemiologic study in a midsized city in northern Italy. Urology, 56, 245-249. doi:10.1016/S0090-4295(00)00643-9

[2] Hunskaar, S. and Vinsnes, A. (1992) The quality of life in women with urinary incontinence as measured by the sickness impact profile. Journal of American Geriatrics Society, 40, 976-977.

[3] Wilson, L., Brown, J.S., Shin, G.P., Luc, K.O. and Subak, L.L. (2001) Annual direct cost of urinary incontinence. American Journal of Obstetrics and Gynecology, 98, 398-406. doi:10.1016/S0029-7844(01)01464-8

[4] Newman, D.K. and Palmer, M.H. (1999) Incontinence and PPS: A new era. Ostomy Wound Management, 45, 32-44.

[5] Abrams, P., Cardozo, L., Fall, M., Griffiths, D., Rosier, P., Ulmsten, U., Von Kerrebroeck, P., Victor, A. and Wein, A. (2003) Standardisation subcommittee of the international continence society. The standardisation of terminology in lower urinary tract function: Report from the standardisation sub-committee of the international conti- 
nence society. Urology, 61, 37-49. doi:10.1016/S0090-4295(02)02243-4

[6] Anger, J.T., Saigal, C.S., Pace, J., Rodriguez, L.V., Litwin, M.S. and the Urologic Diseases of America Project (2006) The true prevalence of urinary incontinence among female nursing home residents. Urology, 67, 281-287. doi:10.1016/j.urology.2005.08.062

[7] Brocklehurst, J.C. (1993) Urinary incontinence in the community-analysis of a MORI poll. British Medicine Journal, 306, 832-834. doi:10.1136/bmj.306.6881.832

[8] Offermans, M.P., Moulin, D., Hamers, J.P., Dassen, T. and Halfens, R.J. (2009) Prevalence of urinary incontinence and associated risk factors in nursing home residents: A systematic review. Neurourology Urodynamics, 28, 288-294. doi:10.1002/nau.20668

[9] Engberg, S., Kincade, J. and Thompson, D. (2004) Future directions for incontinence research with frail elders. Journal of Nursing Research, 53, 6S.

[10] Skelly, J. and Flint, A.J. (1995) Urinary incontinence associated with dementia. Journal of American Geriatrics Society, 43, 286-294.

[11] Dingwall, L. and Mclafferty, E. (2006) Do nurses promote urinary continence in hospitalized older people? An exploratory study. Journal of Clinical Nursing, 15, 12761286. doi:10.1111/j.1365-2702.2006.01381.x

[12] Palmer, M.H. and Newman, D.K. (2004) Bladder matters: Urinary incontinence in nursing homes. American Journal of Nursing, 104, 57-59. doi:10.1097/00000446-200411000-00028

[13] Watson, N., Brink, C.A, Zimmer, J.G. and Mayer, R.D. (2003) Use of the agency for health care policy and research urinary incontinence guideline in nursing homes. Journal of American Geriatrics Society, 51, 1779-1786. doi:10.1046/j.1532-5415.2003.51564.x

[14] Royal College of Physicians (1995) Incontinence. Causes, management and provision of services. A working Party of the Royal College of Physicians. The Royal College of Physicians of London, 29, 272-274.

[15] Omli, R., Skotnes, L.H., Mykletun, A., Bakke, A.M. and Kuhry, E. (2008) Residual urine as a risk factor for lower urinary tract infections: A one year follow up in nursing homes. Journal of American Geriatrics Society, 56, 871874. doi:10.1111/j.1532-5415.2008.01646.x

[16] Omli, R., Skotnes, L.H., Romild, U., Bakke, A.M., Mykletun, A. and Kuhry E. (2010) Pad per day usage, urinary incontinence and urinary tract infections in nursing home residents. Age Ageing, 39, 549-554. doi:10.1093/ageing/afq082

[17] Lubke, N., Meinck, M. and Von Renteln-Kruse, W. (2004) The Bartel Index in geriatrics. A context analysis for the Hamburg Classification Manual. Archives of Gerontolology and Geriatrics, 37, 316-326.

[18] Mahony, F. and Barthel, D. (1965) Functional evaluation: The Barthel Index. Rehabilitation, 4, 61-65.

[19] Borrie, M.J., Campell, K., Arcese, Z.A., Bray, J., Hart, P. and Labate, T. (2001) Urinary retention in patients in a geriatric rehabilitation unit: Prevalence, risk factors, and validity of bladder scan evaluation. Rehabilitation Nurs- ing, 26, 87-191.

[20] Teng, C.H., Huang, Y.U., Kuo, B.J. and Bih, L.I. (2005) Application of portable ultrasound scanners in the measurement of post-void residual urine. Journal of Nursing Research, 13, 216-224. doi:10.1097/01.JNR.0000387543.68383.a0

[21] Resnick, B. (1995) A bladder scan trial in geriatric rehabilitation. Rehabilitation Nursing, 20, 194-196.

[22] Declaration of Helsinki (1964) Archive of British Medical Journal, 313.

[23] Ouslander, J.G. and Schnelle, J.F. (1995) Incontinence in the nursing home. Annals of Internal Medicine, 122, 438-449.

[24] Resnick, N.M., Yalla, S.V. and Laurino, E. (1989) The pathophysiology of urinary incontinence among institutionalized elderly persons. The New England Journal of Medicine, 320, 1-7. doi:10.1056/NEJM198901053200101

[25] Taylor, J.A. and Kuchel, G.A. (2006) Detrusor underactivity: Clinical features and pathogenesis of an underdiagnosed geriatric condition. Journal American Geriatrics of Society, 54, 1920-1932. doi:10.1111/j.1532-5415.2006.00917.x

[26] Kebapci, N., Yenilmez, A., Efe, B., Entok, E. and Deminirustu C. (2007) Bladder dysfunction in type 2 diabetic patients. Neurourology and Urodynamics, 26, 814-819. doi:10.1002/nau.20422

[27] Kaplan, S.A., Te, A.E. and Blaivas, J.G. (1994) Urodynamic findings in patients with diabetic cystopathy. Journal of Urology, 153, 342-344. doi:10.1097/00005392-199502000-00013

[28] Menéndez, V., Cofán, F., Talbot-Wright, R., Ricart, M.J., Gutiérrez, R. and Carretero, P. (1996) Urodynamic evaluation in simultaneous insulindependent diabetes mellitus and end stage renal disease. Journal of Urology, 155, 2001-2004. doi:10.1016/S0022-5347(01)66074-9

[29] Ueda, T., Yoshimura, N. and Yoshida, O. (1997) Diabetic cystopathy: Relationship to autonomic neuropathy detected by sympathetic skin response. Journal of Urology, 157, 580-584. doi:10.1016/S0022-5347(01)65209-1

[30] Kaplan, S.A. and Blaivas, J.G. (1988) Diabetic cystopathy. Journal of Diabetes Complications, 2, 133-139. doi:10.1016/S0891-6632(88)80024-2

[31] Goode, P.S. and Burgio, K.L. (1997) Pharmacologic treatment of lower urinary tract dysfunction in geriatric patients. The American Journal of the Medical Sciences, 314, 262-267. doi:10.1097/00000441-199710000-00010

[32] Hajjar, E.R., Cafiero, A.C. and Hanlon, J.T. (2007) Polypharmacy in elderly patients. The American Journal Geriatric Pharmacotherapy, 5, 345-351. doi:10.1016/j.amjopharm.2007.12.002

[33] Gormley, E.A., Griffiths, D.J., McCracken, P.N. and Harrison, G.M. (1992) Polypharmacy and its effect on urinary incontinence in geriatric population. British Journal of Urology, 71, 265-269. doi:10.1111/j.1464-410X.1993.tb15940.x

[34] Ekundayo, O.J., Markland, A., Lefante, C., Sui, X., Goode, P.S., Allman, R.M., Ali, M., Wahle, C., Thornton, 
P.L. and Ahmed, A. (2009) Association of diuretic use and overactive bladder syndrome in older adults: A propensity score analysis. Archives of Gerontolology and Geriatrics, 49, 64-68. doi:10.1016/j.archger.2008.05.002

[35] Rodhe, N., Englund, L., Mölstad, S. and Samuelsson, E. (2008) Bacturiuria is associated with urge urinary incontinence in older women. Scandinavian Journal of Primary Health Care, 26, 35-39. doi:10.1080/02813430701878250

[36] Palmer, M.H. (1996) Urinary continence: Assessment and Promotion. Aspen Publication, Gaithersburg.

[37] Morris, J. (2007) Behind closed doors. Working with older people. Brighton, 11, 35-39.

[38] Schnelle, J.F., Cadogan, M.P., Dragan, G., Bates-Jensen, B.M., Osterweil, D., Yoshii, J. and Simmons S.F. (2003) A standardized quality assessment system to evaluate incontinence care in the nursing home. Journal of American Geriatrics Society, 51, 1754-1761. doi:10.1046/j.1532-5415.2003.51560.x

[39] Resnick, B., Keilman, L.J., Calabrese, B., Parmelee, P., Lawhorne, L., Pailet, J. and Ouslander, J. (2006) Nursing staff beliefs and expectations about continence care in nursing homes. Journal of Wound, Ostomy and Continence Nursing, 6, 610-618. doi:10.1097/00152192-200611000-00004

[40] Mangnall, J., Taylor, P., Thomas, S. and Watterson, L. (2006) Continence problems in care homes: Auditing assessment and treatment. International Journal of Older People Nursing, 18, 20-22.

[41] Smith, D.B. (1998) The culture of long-term care: Impact on a continence care program. Urologic Nursing, 18, 291295.

[42] MacDonald, C.D. and Butler, L. (2007) Silent no more: Elderly women's stories of living with urinary incontinence in long-term care. Journal of Gerontological Nursing, 33, 14-20.

[43] Peet, S.M., Castleden, C.M., McGrother, C.W. and Duffin, H.M. (1996) The management of urinary incontinence in residential and nursing homes for older people. Age Ageing, 25, 139-143. doi:10.1093/ageing/25.2.139 